\title{
Total hydrolysis of a new imidazolidine induced by $\mathrm{Zn}^{\text {II }}$
}

Matilde Fondo $^{\mathrm{a}}$, Jesús Doejo ${ }^{\mathrm{a}}$, Ana M. García-Deibe, ${ }^{\mathrm{a}}$ Jesús Sanmartín ${ }^{\mathrm{a}}$, Concepción González-Bello ${ }^{\mathrm{b}}$

${ }^{a}$ Departamento de Química Inorgánica, Facultad de Química, Universidad de Santiago de

Compostela, E-15782 Santiago de Compostela, Spain

${ }^{\mathrm{b}}$ Centro Singular de Investigación en Química Biológica y Materiales Moleculares (CIQUS), Universidad de Santiago de Compostela, c/ Jenaro de la Fuente s/n, 15782 Santiago de Compostela, Spain

E-mail: matilde.fondo@usc.es

\begin{abstract}
2,2'-(2-(2-hydroxyphenyl)imidazolidin-1,3-diyl)diethanol $\left(\mathrm{H}_{3} \mathrm{~L}\right)$ was obtained by condensation between 2-hydroxybenzaldehyde and $N, N$-bis(2-hydroxyethyl)ethylenediamine. Its potential ability as $N N O O O$ donor towards $\mathrm{Zn}^{\text {II }}$ was tested. This study shows that zinc(II) mediates the fast hydrolysis of $\mathrm{H}_{3} \mathrm{~L}$, yielding the free aldehyde and amine. This latter was crystallographically characterised, showing a supramolecular 1D architecture based on hydrogen bond interactions.
\end{abstract}

Keywords: imidazolidine / hydrolysis / zinc / 1D ladder

\section{Introduction}

Imidazolidines are a well-known class of organic compound of growing interest, due to their numerous pharmaceutical applications, such as anticarcinogenic [1], hypotensor [2] or antibacterial agents [3]. In spite of this, the ability of this kind of donor to bind to metal atoms is still scarcely explored. As a continuation of our studies in the interaction of imidizolidine ligands with $d$-block metal ions [4], we describe herein the synthesis of the $\mathrm{H}_{3} \mathrm{~L}$ (Scheme 1) and its stability in the presence of $\mathrm{Zn}^{\mathrm{II}}$.

\section{Results and discussion}

$\mathrm{H}_{3} \mathrm{~L}$ was obtained according to Scheme 1
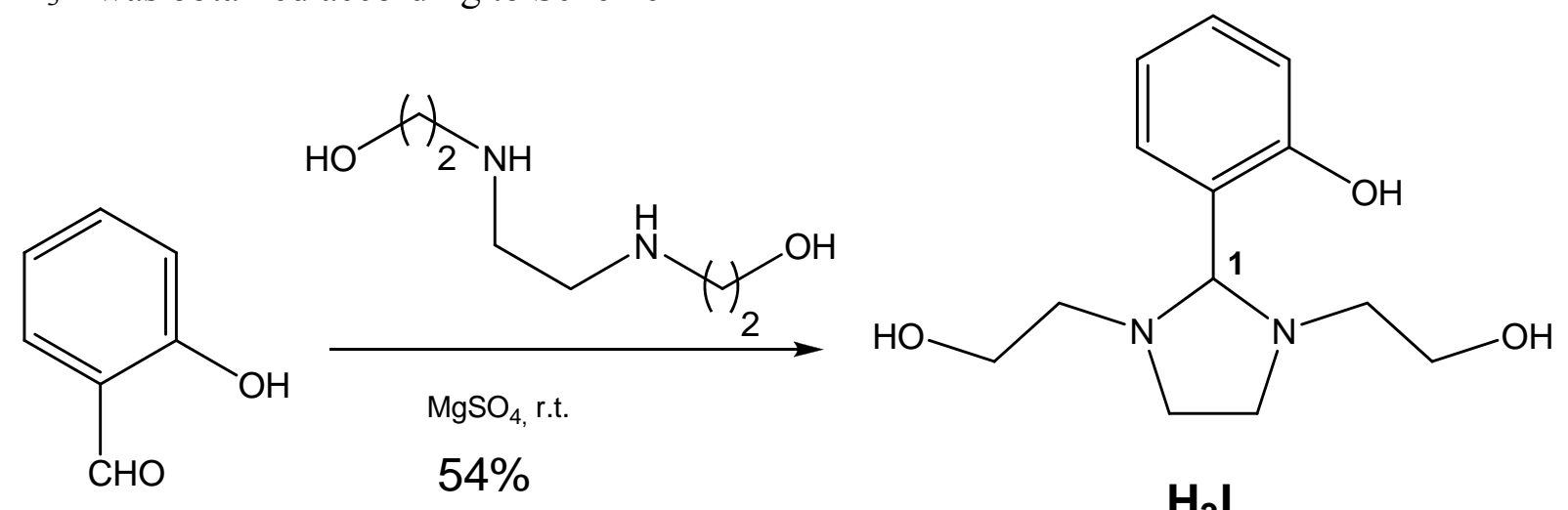

\section{Scheme 1}

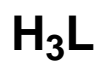

Analytical and spectroscopic data corroborate the isolation of the desired compound, with formation of the imidazolidine ring. Thus, $\mathrm{H} 1$ and $\mathrm{C} 1$ atoms (Scheme 1) appear in the ${ }^{1} \mathrm{H}$ and ${ }^{13} \mathrm{C}$ NMR spectra at $3.81 \mathrm{ppm}$ (singlet) and $88.9 \mathrm{ppm}$, respectively, and the mass spectrum $\left(\mathrm{ESI}^{-}\right)$shows the molecular peak at $\mathrm{m} / \mathrm{z} 251(\mathrm{M}-\mathrm{H})$.

The reaction of $\mathrm{H}_{3} \mathrm{~L}$ towards $\mathrm{Zn}(\mathrm{OAc})_{2}$ was tested. This reaction leads to a yellow oil, whose spectroscopic characterisation clearly shows that the ligand suffers hydrolysis. Thus, the oil is really a mixture, composed of the free zinc acetate, amine and aldehyde (Figure 1). These species could be unequivocally identified by comparison of the ${ }^{1} \mathrm{H}$ NMR spectrum of the oil with those of the free compounds. In this way, it should be noted that the hydrolysis of the ligand is clearly demonstrated by the presence of a new singlet at $9.86 \mathrm{ppm}$ and the total absence of the singlet at $3.81 \mathrm{ppm}$, corresponding to $\mathrm{H} 1$. 


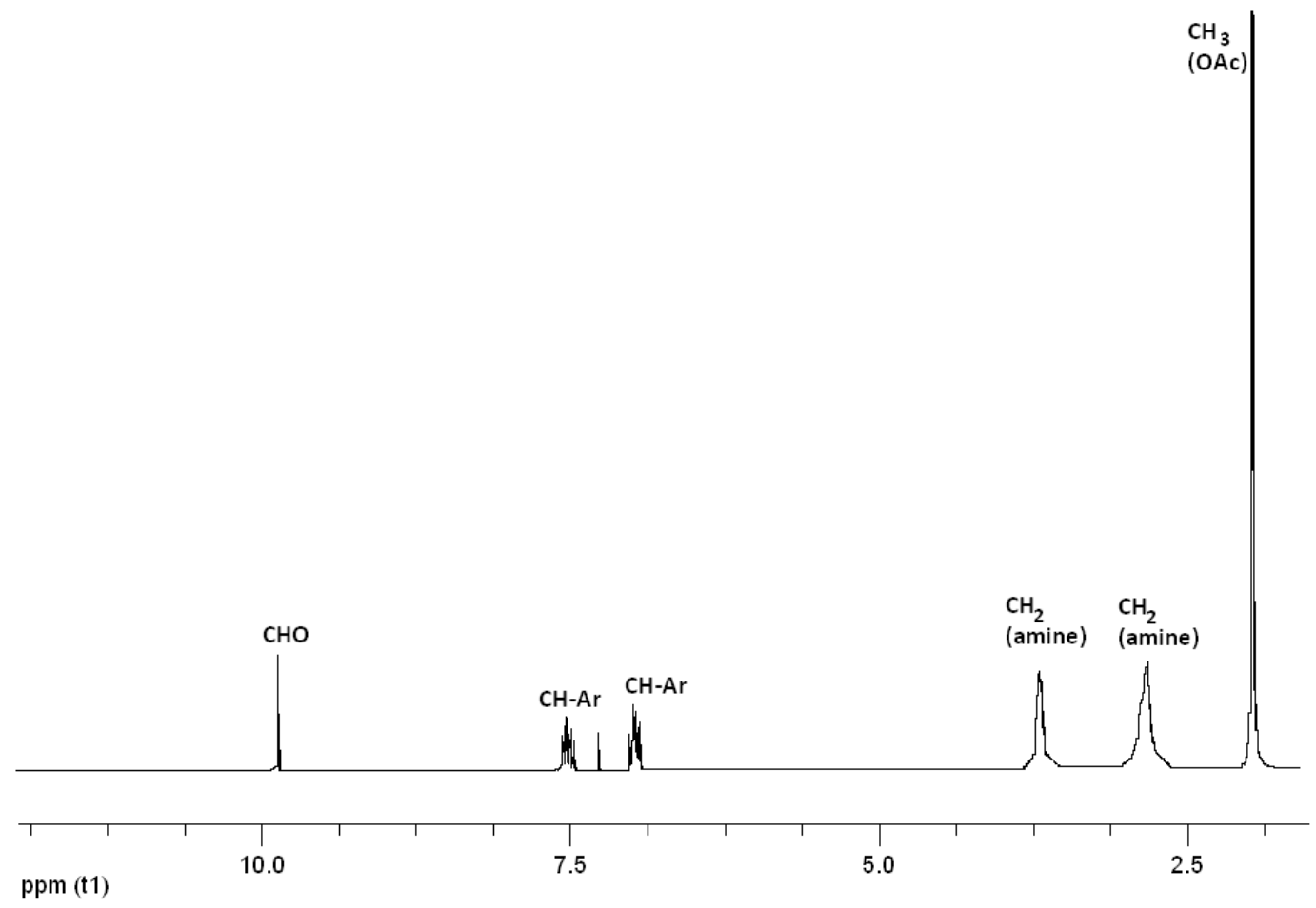

Fig. 1. ${ }^{1} \mathrm{H}$ NMR spectrum of the oil in $\mathrm{CDCl}_{3}$

This result indicates that the presence of the 2-hydroxyethyl residues makes extremely labile the $\mathrm{C} 1-\mathrm{N}$ bond in $\mathrm{H}_{3} \mathrm{~L}$. This can be stated because many zinc complexes with similar ligands, lacking 2-hydroxyethyl groups, have been previously isolated without any evidence of hydrolysis [5].

The hydrolysis of $\mathrm{H}_{3} \mathrm{~L}$ and the presence of the free amine in the oil mixture could also be unequivocally established by single X-ray diffraction studies. Thus, the free amine was isolated from the mixture in the form of single crystals. A perspective view of the molecule is shown in Figure 2. All the angles and distances are in the range of those expected for this kind of compound and do not deserve further consideration. Therefore, just to note that the amine has an inversion centre in the middle of the molecule, being both halves equivalent.

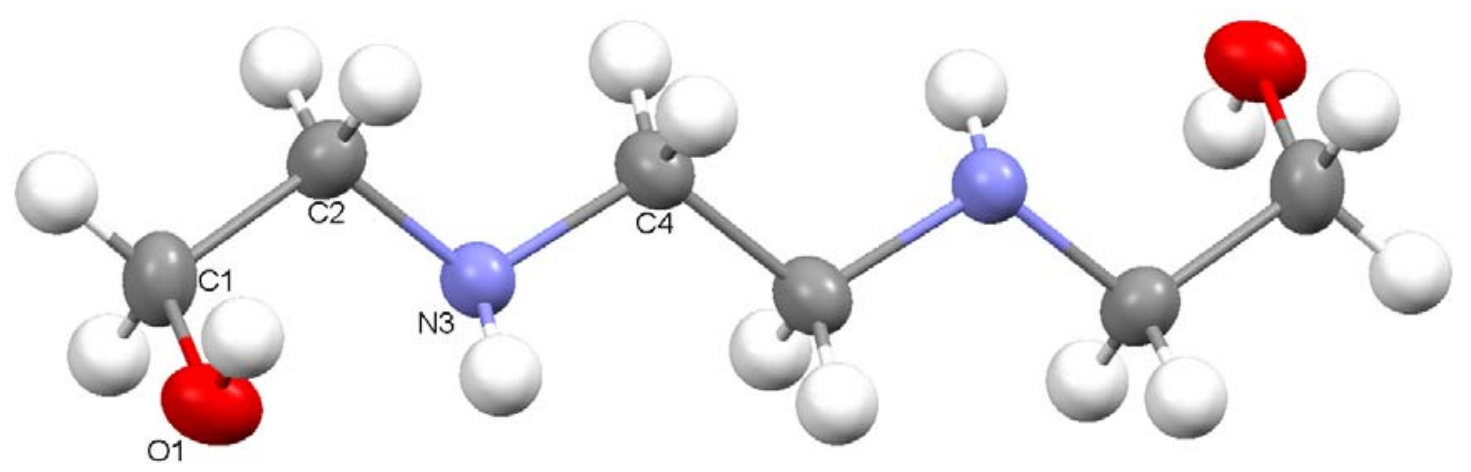

Fig. 2. Ellipsoid diagram for $\mathrm{H}_{3} \mathrm{~L}$. Only the non-H atoms of the asymmetric unit are labelled.

In addition, it is remarkable that both the amine and hydroxyl groups are involved in hydrogen bonds. These interactions expand the initial molecule into a 1D solid. Thus, the overall structure of the amine can be described as a supramolecular ladder (Figure 3). 


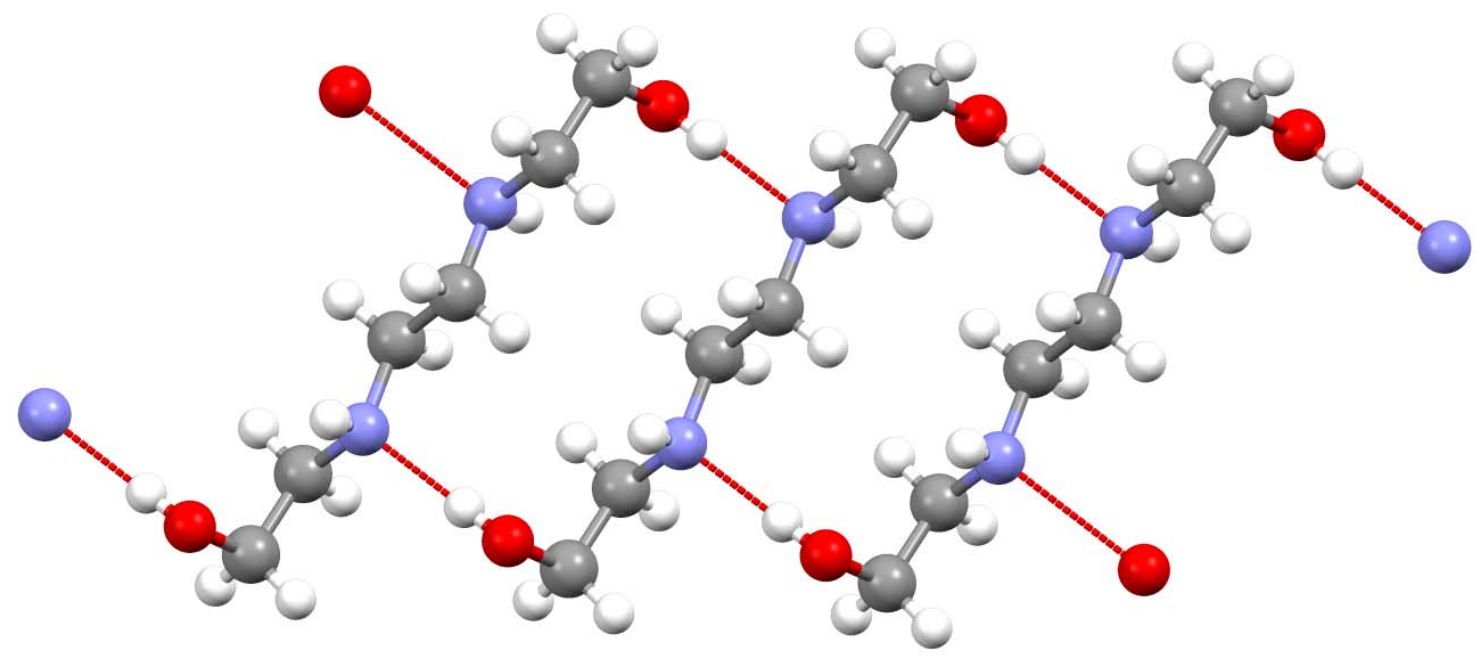

Fig. 3. Hydrogen bond scheme for $\mathrm{H}_{3} \mathrm{~L}$

\section{Conclusions}

The new imidazolidine derivative $\mathrm{H}_{3} \mathrm{~L}$ was prepared with high yield and purity. The reactivity of the organic compound towards $\mathrm{Zn}{ }^{\mathrm{II}}$ shows that the $\mathrm{C} 1-\mathrm{N}$ bond is extremely unstable in the occurrence of this metal ion, suffering complete hydrolysis. This process leads to a mixture of 2-hydroxybenzaldehyde, $N, N$ '-bis(2-hydroxyethyl)ethylenediamine and the zinc(II) salt. The high instability of this bond is associated with the presence of the 2-hydroxyethyl residue.

The X-ray structure of the free amine, obtained from the final crude of the reaction, shows an extended hydrogen bond scheme that expands the initial amine node into an infinite ladder.

\section{Experimental}

\section{Synthesis of $\mathrm{H}_{3} \mathrm{~L}$}

$\mathrm{H}_{3} \mathrm{~L}$ was isolated as follows: to a solution of 2-hydroxybenzaldehyde (4.72 $\left.\mathrm{ml}, 64 \mathrm{mmol}\right)$ in absolute ethanol (200 mL), N,N'-bis(2-hydroxyethyl)ethylenediamine (9.61 g, $64.84 \mathrm{mmol})$ and $\mathrm{MgSO}_{4}$ were added. The resultant suspension was stirred at room temperature for $16 \mathrm{~h}$. and then filtered. The obtained oil was purified by recrystallisation in ethylacetate, giving rise to $\mathrm{H}_{3} \mathrm{~L}(8.65 \mathrm{~g}, 54 \%)$, as yellow crystals. m.p.: 83-88 ${ }^{\circ} \mathrm{C}$. Elemental analysis: found: $\mathrm{C}$, 61.76; $\mathrm{H}, 8.47 ; \mathrm{N}, 11.21$; calcd. for $\mathrm{C}_{13} \mathrm{H}_{20} \mathrm{~N}_{2} \mathrm{O}_{4} \mathrm{C}, 61.90 ; \mathrm{H}, 7.93 ; \mathrm{N}, 11.21$. ${ }^{1} \mathrm{H}-\mathrm{RMN}(250$ $\left.\mathrm{Hz}, \mathrm{CDCl}_{3}\right) \delta: 7.20(\mathrm{dt}, J=1.8$ and $8.0 \mathrm{~Hz}, 1 \mathrm{H}, \mathrm{ArH}), 6.96(\mathrm{dd}, J=1.5$ and $7.8 \mathrm{~Hz}, 1 \mathrm{H}, \mathrm{ArH})$, $6.80(\mathrm{~m}, 2 \mathrm{H}, 2 \times \mathrm{ArH}), 3.81(\mathrm{~s}, 1 \mathrm{H}, \mathrm{CH}), 3.63-3.42\left(\mathrm{~m}, 6 \mathrm{H}, 3 \times \mathrm{CH}_{2}\right), 2.79\left(\mathrm{~m}, 2 \mathrm{H}, \mathrm{CH}_{2}\right), 2.60$ $\left(\mathrm{m}, 2 \mathrm{H}, \mathrm{CH}_{2}\right)$ and $2.39\left(\mathrm{td}, J=4.1\right.$ and $\left.12.5 \mathrm{~Hz}, 2 \mathrm{H}, \mathrm{CH}_{2}\right) \mathrm{ppm} .{ }^{13} \mathrm{C}-\mathrm{RMN}\left(63 \mathrm{MHz}, \mathrm{CDCl}_{3}\right)$

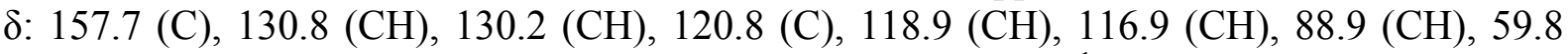
$\left(2 \times \mathrm{CH}_{2}\right), 54.0\left(2 \times \mathrm{CH}_{2}\right)$ and $49.9\left(2 \times \mathrm{CH}_{2}\right) \mathrm{ppm}$. IR $\left(\mathrm{ATR}, v / \mathrm{cm}^{-1}\right): 3404(\mathrm{~b}), 3500(\mathrm{sh})(\mathrm{OH})$. MS (ESI-) $\mathrm{m} / \mathrm{z}$ found, 251.1385; calcd. for $\mathrm{C}_{13} \mathrm{H}_{20} \mathrm{O}_{3} \mathrm{~N}_{2}(\mathrm{M}-\mathrm{H})$.

\section{Reaction of $\mathrm{H}_{3} \mathrm{~L}$ with $\mathrm{Zn}^{\text {II }}$}

To a solution of $\mathrm{H}_{3} \mathrm{~L}(0.05 \mathrm{~g}, 0.2 \mathrm{mmol})$ in acetonitrile $(10 \mathrm{~mL})$, a solution of $\mathrm{Zn}(\mathrm{OAc})_{2} \cdot 4 \mathrm{H}_{2} \mathrm{O}$ $(0.087 \mathrm{~g}, 0.4 \mathrm{mmol})$ was added. The resultant solution was stirred at room temperature for 1 h. and concentrated to dryness. The obtained yellow oil was characterised by ${ }^{1} \mathrm{H}$ NMR spectroscopy. ${ }^{1} \mathrm{H}-\mathrm{RMN}\left(250 \mathrm{~Hz}, \mathrm{CDCl}_{3}\right) \delta: 9.86(\mathrm{~s}, 1 \mathrm{H}, \mathrm{CHO}), 7.55-7.46(\mathrm{~m}, 2 \mathrm{H}, \mathrm{ArH}), 7.01-$ $6.93(\mathrm{~m}, 2 \mathrm{H}, \mathrm{ArH}), 3.76-3.63\left(\mathrm{~m}, \mathrm{CH}_{2}\right), 2.74-2.73\left(\mathrm{~m}, \mathrm{CH}_{2}\right), 1.93\left(\mathrm{~s}, \mathrm{CH}_{3}-\mathrm{OAc}\right) \mathrm{ppm}$.

Attempts of recrystallisation of the crude oil in ethylacetate yield single crystals of $N, N$-bis(2-hydroxyethyl)ethylenediamine, suitable for X-ray diffraction studies. Crystal data: (at $100(2) \mathrm{K}$ ): monoclinic, $P 2_{1} / n, \mathrm{C}_{6} \mathrm{H}_{16} \mathrm{~N}_{2} \mathrm{O}_{2}, \quad M W=148.21$, with $a=9.944(5) \AA$, $b=8.778(54) \AA, c=18.967(5) \AA$ and $\beta=92.306(5), V=398.77(7) \AA^{3}, Z=2 ; R_{1}=0.0326$ and $w R_{2}=0.0846(I>2 \sigma I)$. 


\section{References}

[1]. M. A. Khanfar, K. A. Sayed, Eur. J. Med. Chem. 2010, 45, 5397.

[2] L. A Al-Sinawi, Q.A Mekki, S. Hassan, A. Hedges, C. Burke, S. G. Moody, J. O'Grady, Prostaglandins, 1985, 29, 99.

[3] F. Fujisaki, K. Toyofuku, M. Egami, S. Ishida, N. Nakamoto, N. Kashige, F. Miake, K. Sumoto, Chem. Pharm. Bull. 2013, 61, 1090.

[4] M. Fondo, N. Ocampo, A. M. García-Deibe, J. Sanmartín, I. García-Santos, A.J. Mota, J. L. Pérez-Lustres, Dalton Trans. 2011, 40, 11770.

[5] A.M. García-Deibe, M. Fondo, N. Ocampo, J. Sanmartín, E. Gómez, New J. Chem. 2010, 34,1073 and references therein. 